\title{
A Quality Improvement Method of Diesel Engine based on QFD and TRIZ
}

\begin{abstract}
Xuguang Tan
Weichai Power Co., Ltd., Weifang, China

Keywords: quality function deployment, Theory of Innovation Problem Solving, quality improvement

Abstract: On the basis of Quality Function Deployment (QFD) and Theory of Innovation Problem Solving (TRIZ), this paper proposed a method of diesel engine quality improvement. First, we introduced the theoretical background briefly. Secondly, we combine scenario analysis (5W1H) method, KJ (affinity diagram) method, AHP (analytic hierarchy process) method and other tools to building the house of quality which effectively transforming customer requirement into technical characteristics. And the value order of customer requirement is reflected in the choice of technical characteristics, so that the design scheme to meet customer requirement can be determined. Then, the conflict of technical characteristics (indicators) in the design scheme is analyzed and resolved. Finally, the comprehensive optimization design scheme is obtained, which points out the innovation path for diesel engine conceptual design.
\end{abstract}

\section{Introduction}

With the development of economy and society, market competition is becoming increasingly fierce, product life cycle is becoming shorter and shorter, customers are becoming more and more selective in choosing products [1-3]. So the internal and external environment that enterprises are facing is becoming more and more complex. Enterprises must create new products to meet customers' needs in the shortest possible time in order to maintain their own competitive advantage [4]. In order to gain competitive advantage, an enterprise must rely on continued product innovation. Under such circumstances, there is a need for finding new product development technologies to develop new product which can bring customer satisfaction [5].

In recent years, many scholars have done a great deal of research on innovative application theories such as Quality Function Deployment (QFD), Theory of Innovation Problem Solving (TRIZ). For example, Melemez, \& Gironimo(2013) design of a timber trailer capable of manual loading operations and suitable for rough terrain conditions to be used in combination with a farm tractor in the western[11]; Yeh et al.,(2011) develop and market an environmentally friendly and energy-efficient notebook computer based on QFD and TRIZ[19]. Su and Lin (2008) proposed a model based on TRIZ methodology to generate creative solutions for service quality improvement by examining service quality determinants first, then using Fuzzy QFD to analyze correlation between imprecise customer requirements and service quality determinants [13]. Wang et al.,(2005) describe an algorithm that can integrate QFD and TRIZ effectively for the purpose of the innovative 
design process[17]. Yamashina et al. (2002) proposed the Innovative Product Development Process (IPDP), which systematically integrates QFD with TRIZ and enables the effective and systematic creation of technical innovation for new products[18]. Wang and Chang (2007) integrated TRIZ innovations to assist designers identify rules to meet customer requirements and avoid bad design. After deployment of all concept design rules, FMEA (Failure Mode and Effect Analysis) was applied to prove products and analyze all subsystem weight values[16]. On the other hand, some papers studied the use of QFD to support the TRIZ process. Schlueter (2001) relates TRIZ concepts such as absent or available useful functions, harmful functions, and ideality to the Kano model, as described by Cohen (1995). Li et al. (2009) analyzed QFD's defects and investigated the possibilities for integrated use of QFD and TRIZ based on their respective appearance, development, content and application characteristics[9].

\section{Theoretical Background}

Quality Function Deployment (QFD) proposed by Professor Yoji Akao, which is a multi-level deductive analysis, transforming customer requirement into a series of technical characteristics of product development and design process, taking market as the guide and customer requirement as the basis[3]. QFD is a systematic and technical method to ensure the applicability of products in the initial stage of development and design. The core content of QFD is customer demand conversion, which is in the form of House of Quality[8]. It is an intuitive matrix framework expression and a tool of QFD method. Establishing the basic framework of the house of quality, which give the input information, and get the output information through analysis and evaluation, and then convert the requirement into the method of product design scheme[6,7].

TRIZ is the theory of resolving the conflict of engineering technical parameters, which was summarized by a group of researchers headed by G.S. Altshuller of the former Soviet Union. It can almost be used in all stages of product lifecycle. It is closely related to the development of highquality products, the acquisition of high benefits, the expansion of the market, the innovation of products, the analysis of product failure, the protection of independent intellectual property rights and the development of next generation products[9,11]. TRIZ conflict matrix is an important method to solve problems. It provides designers with another way to analyze and solve problems. Once the designer grasps this new method, it will bring a lot of new ideas to solve conflicts / contradictions $[15,16]$.

QFD takes the customer requirement as the starting point, and uses one or more house of quality matrix diagrams to gradually transform the user's needs into the product's functional requirements, design requirements and manufacturing process characteristics[17]. In the process of transformation, QFD can excavate key innovation problems and key design areas to solve customer pain points, but it cannot put forward specific innovation problem solving methods and solving tools. The TRIZ theory abstracts the specific parameters in the design into 39 general engineering parameters (later expanded to 48 engineering parameters) and 40 basic inventive principles. TRIZ theory is used to judge whether there is any conflict between customer requirements and the conversion of functional characteristics, functional requirements and design schemes. If there is a conflict, identify the type of confliction, and according to the principle of invention to find the most likely technical measures to resolve the conflict, the implementation of conflict resolution[10,18].

\section{Research Framework}

This research takes QFD as the main line, combines scenario analysis, KJ method (affinity diagram), AHP method (analytic hierarchy process), TRIZ theory and methods to build a product innovation design model based on QFD. By effectively transforming customer needs into technical 
measures and reflecting the value order of customer needs into the choice of technical measures, the design scheme to meet customer needs can be determined. Then, the technical measures (indicators) which have conflicts in the design scheme are analyzed and resolved, and finally the comprehensive optimization design scheme is obtained. This model is mainly composed of three sub models:

\subsection{Product conceptual design sub model.}

The model is mainly used for product conceptual design. The main contents include the acquisition of customer requirements, hierarchical clustering analysis of requirements and value ranking, as well as the quality planning of customer requirements. Firstly, the customer requirements are mined and identified, and the original customer requirements are sorted out by scenario analysis $(5 \mathrm{~W} 1 \mathrm{H}$, who, why, when, what, where, how) method. Then the customer requirements are clustered by KJ (affinity graph) method, so that similar requirements items can be classified into one class or the same level. Then the current more accurate AHP (Analytic Hierarchy Process) method is used to evaluate the importance of the hierarchical customer requirements, and the order of customer value to the needs is obtained. Finally, according to the market competitiveness evaluation of customer requirements, the quality planning of customer requirements is carried out.

\subsection{Product design solution sub model}

The model is mainly used for Product design solution. The main structure of the model is the house of quality in QFD theory, which is used to transfer customer requirements to designers accurately. Through the relationship matrix evaluation of the house of quality (HOQ), the importance ranking of customer requirements can be transformed into the importance ranking of technical characteristics. According to the ranking of importance of technical characteristics and the evaluation of technical competitiveness, the designer sets the target value of technical characteristics to determine the product design solution.

\subsection{Conflict resolution sub model.}

The roof correlation matrix of the house of quality represents the correlation between design parameters, because different technical characteristics have synergistic or conflicting effects. We use the HOQ technology to find out the correlation between quality characteristics. For the negative correlation problems in the autocorrelation matrix of quality characteristics, TRIZ is used to analyze conflicts, determine conflicts and resolve conflicts. Firstly, conflict analysis is carried out on the negative correlation parameters in the correlation matrix of the house of quality. Secondly, judging the types of conflicts according to the criteria of different conflicts, and consulting the matrix of conflict resolution to find solutions, to provide design and development ideas to solve the problem.

\section{Case Study}

\subsection{Research background}

As we all know, diesel engine is a mechanical device with a complex structure. It not only has a large number of components and complex structure, but also has a complex relationship between system assembly and movement. Therefore, the design of the diesel engine is difficult and timeconsuming. This paper applies the conceptual design model to the product development of a diesel engine $R \& D$ center. However, it is a new attempt to apply QFD theory to the research and 
development of diesel engines. By using the Home of Quality technology, the importance of customer requirements can be translated into the importance of technical characteristics that designers are concerned about. Based on the importance of technical features, designers can determine which technical features need to be met first and need to invest more resources to ensure that. And the technical conflict analysis of diesel engine is studied.

\subsection{House of quality for diesel engines}

In order to ensure the validity of the research results, we has completed the following work to ensure that real data and results are obtained: Because of the specialty of diesel engine knowledge, we initially carried out a lot of information collection and literature research on diesel engine. Interview some diesel engine operators, especially some diesel designers. Consult diesel design experts to confirm customer needs and technical characteristics.

Questionnaires were conducted among nearly six diesel engine designers to rank the importance of customer requirements. According to the customer requirements and technical characteristics, a conceptual design house of quality for diesel engines was constructed on the basis of the results, and QM3 (Quantification Method of Type 3) was used for quantitative analysis.

Above, we get the quality house of diesel engine (Part 2), as shown in Figure 1. From Figure 1, we can see that the Importance orders of the TCs are as follows (See Table 1):

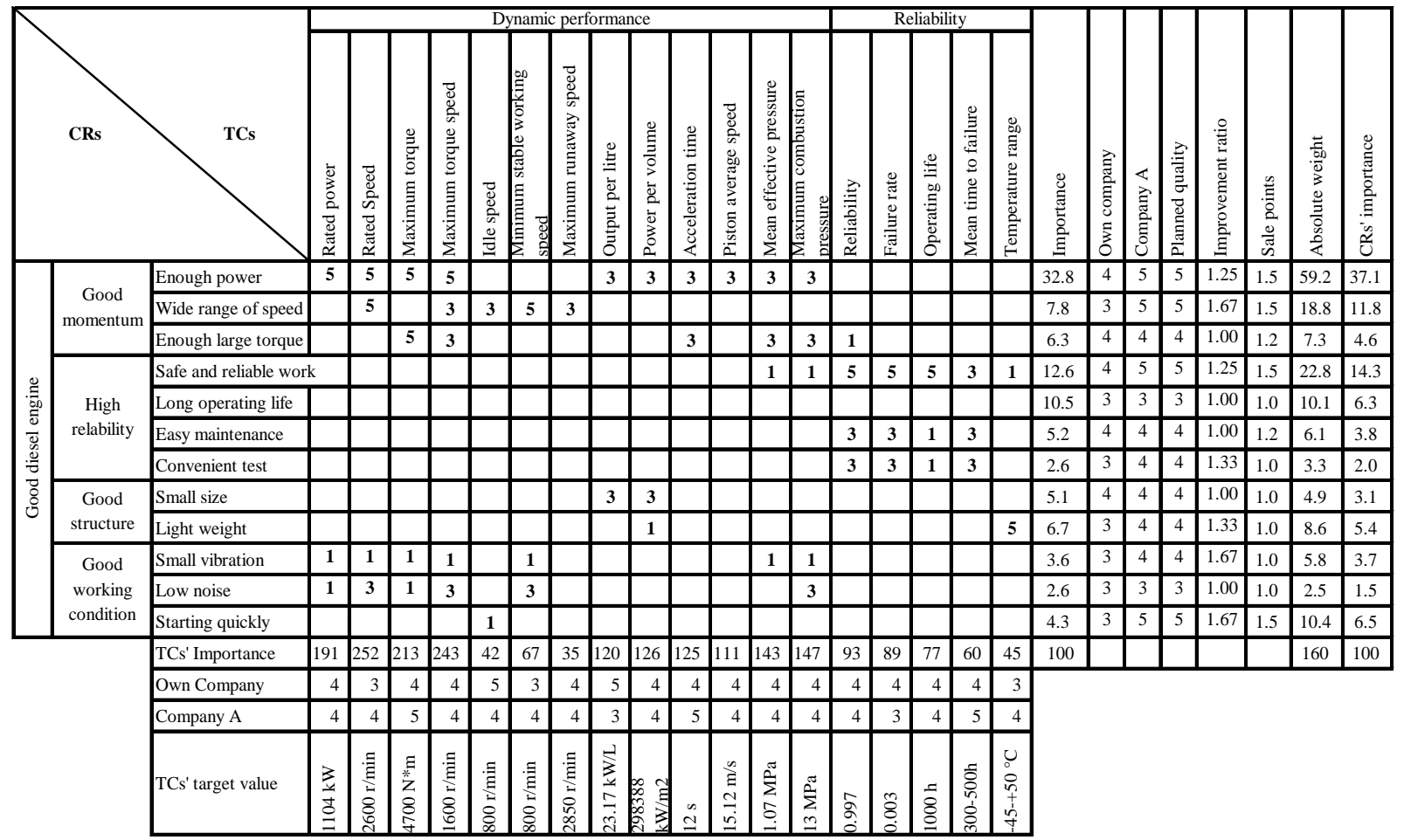

Relationship Matrix: (O)=Strong=5, $\circ=$ Medium=3, $\triangle=$ Weak=1

Figure 1. The House of Quality (HOQ) of the diesel engine (partial). 
Table 1. The importance order of the Technical Characteristics (partial).

\begin{tabular}{|c|c|c|c|}
\hline Importance Order & Technical Characteristics & $\begin{array}{c}\text { Importance } \\
\text { weight }\end{array}$ & Target value \\
\hline 1 & Rated Speed & 252 & $2600 \mathrm{r} / \mathrm{min}$ \\
\hline 2 & Maximum torque speed & 243 & $1600 \mathrm{r} / \mathrm{min}$ \\
\hline 3 & Maximum torque & 213 & $4700 \mathrm{~N} * \mathrm{~m}$ \\
\hline 4 & Rated power & 191 & $1104 \mathrm{~kW}$ \\
\hline 5 & Maximum combustion & 147 & $13 \mathrm{MPa}$ \\
\hline 6 & pressure & 143 & $1.07 \mathrm{MPa}$ \\
\hline 7 & Mean effective pressure & 126 & 298388 \\
$\mathrm{~kW} / \mathrm{m} 2$ \\
\hline 8 & Power per volume & 125 & $12 \mathrm{~s}$ \\
\hline 9 & Output per litre & 120 & $23.17 \mathrm{~kW} / \mathrm{L}$ \\
\hline 10 & Piston average speed & 111 & $15.12 \mathrm{~m} / \mathrm{s}$ \\
\hline 11 & Reliability & 93 & 0.997 \\
\hline 12 & Failure rate & 89 & 0.003 \\
\hline 13 & Operating life & 77 & $1000 \mathrm{~h}$ \\
\hline 14 & Minimum stable working & 67 & $800 \mathrm{r} / \mathrm{min}$ \\
\hline 15 & speed & 60 & $300-500 \mathrm{~h}$ \\
\hline 16 & Mean time to failure & 42 & $800 \mathrm{r} / \mathrm{min}$ \\
\hline 17 & Idle speed & 35 & $2850 \mathrm{r} / \mathrm{min}$ \\
\hline 18 & Maximum runaway speed & 45 & $-45-+50{ }^{\circ} \mathrm{C}$ \\
\hline
\end{tabular}

According to the importance order of technical characteristics (technical indicators) and the target value of technical characteristics, we can determine the design scheme of a diesel engine product. In this design, those important design indicators are the focus of attention of designers, such as: Rated Speed, Maximum torque speed, Maximum torque and other technical characteristics. Designers must first meet the design indicators of high importance.

And some unimportant technical characteristics (indicators) do not need to invest a lot of design energy and cost. For example: Mean time to failure, Idle speed, Maximum runaway speed, Temperature range and other technical characteristics. Therefore, QFD technology can be used to rank the importance of customer reqirement into the importance of technical characteristics, thus helping designers to determine a product design.

\subsection{Solutions to resolve technological contradictions}

\subsubsection{Autocorrelation matrix of engine technical characteristics}

The autocorrelation matrix of technical characteristics here requires more experienced experts to score. If measures to improve one technical feature contribute to the improvement of another, we define a positive correlation between the two technical features. On the contrary, if the improvement of one technical feature will have a negative impact on the other, we define that the 
two technical features are negatively correlated. We use $\circ$ indicates that two technical characteristics are positively correlated, and $\times$ means two technical characteristics are negatively correlated. The panel's evaluation results are shown in table 2.

Table 2 autocorrelation matrix of engine technical characteristics (partial)

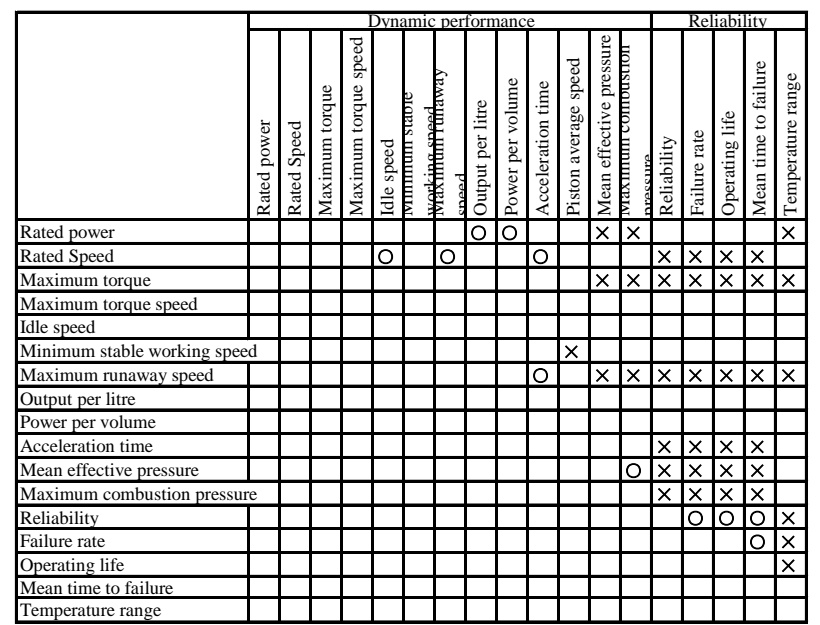

\subsubsection{Technical characteristics conflict}

The technical characteristics conflict is evaluated by the autocorrelation matrix of the technology property of the house of quality, as shown in table 3.

Table 3 technical characteristics of negative correlation (partial)

\begin{tabular}{|l|l|}
\hline \multirow{3}{*}{ Rated power } & Mean effective pressure \\
\cline { 2 - 2 } & Maximum combustion pressure \\
\cline { 2 - 2 } & Temperature range \\
\hline Temperature range & Reliability \\
\hline
\end{tabular}

For example, for a diesel engine, we want it to increase in power, the mean effective pressure decreases. But in fact, the increase of engine calibration power will result in an increase in average effective pressure. Therefore, there is a conflict between the technical characteristics of engine "Rated power" and "mean effective pressure ".

\subsubsection{Technical conflict resolution}

The conflict analysis method of TRIZ is to abstract the negative correlation technical characteristics into the technical characteristics which need to be improved and worsened in the TRIZ conflict matrix. The conflict matrix can give several principles to solve the negative correlation of technical characteristics and improve the performance of parts. For example, the rise of the engine's operating "temperature range" will result in a decrease in the engine's operating "reliability", so there is a technical conflict between the engine's operating "temperature range" and "reliability". Specifically to the components of the engine, the cylinder and piston systems are closely related to the two technical characteristics of "temperature range" and "reliability". So we take the cylinder and piston of the engine as the research object. The "temperature range" and "reliability" are abstracted as the technical characteristics to be improved respectively. To solve the problem, we should first clarify the technical system that caused the problem. In this case, the technical system that causes the problem is the engine cylinder piston combustion system.

In order to improve the working temperature range of the engine, that is to say, when working 
in a high temperature environment, the reliability of piston and cylinder decreases. The thermal deformation of piston increases, which may cause large gap between cylinder and piston, resulting in power loss and affecting the reliability of piston engine.

First, we need to identify the characteristics that must be improved in the technical system. It points out the characteristics that need improvement, and finds out the technical conflict, and then solves the technical conflict.

We refer to the conflict matrix comparison table to find technical conflicts. The characteristic "temperature range" corresponds to the 17 rows in the table, and the characteristic "reliability" related to the characteristic "reliability" is the "reliability" of column 27. Looking at the technical conflict matrix table, the recommended invention principles are shown in the table 4.

Table 4 TRIZ for technological conflict

\begin{tabular}{|l|l|c|l|}
\hline Technical conflict & $\begin{array}{l}\text { Intersection point in } \\
\text { table }\end{array}$ & Principle & Principle name \\
\hline & & 19 & $\begin{array}{l}\text { Periodic action } \\
\text { principle }\end{array}$ \\
\cline { 3 - 4 } $\begin{array}{l}\text { Temperature } \\
\text { reliability }\end{array}$ & 35 & $\begin{array}{l}\text { Parameter } \\
\text { variation } \\
\text { principle }\end{array}$ \\
\cline { 3 - 4 } & $17 \times 27$ & 3 & $\begin{array}{l}\text { Local quality } \\
\text { principle }\end{array}$ \\
\cline { 3 - 4 } & 10 & $\begin{array}{l}\text { pre operation } \\
\text { principle }\end{array}$ \\
\hline
\end{tabular}

After comparative analysis, we apply the second rule of principle 3, the Local quality principle, which states that different parts of an object perform different functions. We can make the outer part of the piston made of wear-resistant and heat-resistant material. The inner core material is made of easy-to-conduct heat material and connected to the connecting rod for air cooling or lubricating oil cooling. There by improving the local thermal state of the piston, reducing the temperature of the piston and reducing the deformation.

In this study, a technical conflict analysis method of diesel engine is given, and all other technical characteristic conflicts can be solved according to this method.

\section{Conclusions}

The QFD model of diesel engine conceptual design constructed in this study can transform customer requirement information into technical characteristics and design scheme in the process of product innovation design reasonably and effectively. This research takes QFD as the main line, uses a series of methods (scenario analysis, KJ method, AHP method) to obtain, transform, extract and mine the real needs of customers. The HOQ is used to describe the interaction between the attributes of product requirements and visualize the analysis, so as to make the requirements fully and completely [14]. The importance of customer needs is transferred to the importance of technical characteristics of designers by building a "customer demand-technical characteristics" quality house. So as to provide design guidelines for designers, so that product design can truly meet the requirement of customer.

By using the quality house (HOQ) technology of QFD, the autocorrelation matrix of technical characteristics can be constructed to express the "collaborative" or "conflict" relationship between technical characteristics. Then, TRIZ (Inventive Problem Solving Theory) is used to analyze the technical characteristics of the negative correlation in the autocorrelation matrix of the house of 
quality, and TRIZ conflict matrix is used to determine the types of conflicts and find a way to resolve the conflicts between the technical parameters of the products. In product conceptual design, QFD theory can be used to discover conflicts existing in products or systems. The advantage of TRIZ theory is to analyze conflicts and problems and propose innovative solutions, but TRIZ theory does not propose a systematic method to find problems and conflicts. This study proposes a new method of product conceptual design, which combines the complementary advantages of QFD and TRIZ, combines QFD and TRIZ systematically, and links the way of thinking of putting forward, analyzing and solving problems systematically. TRIZ is applied to analyze the technical elements of product design with negative correlation in HOQ. The categories of management conflict, technical conflict and physical conflict are determined according to TRIZ conflict criterion. The method of resolving technical conflict is sought through the TRIZ, the impulse between technical parameters of new product design is solved. Suddenly, to obtain innovative design to meet customer needs can eliminate some of the risk of relying on random luck in product development process.

\section{References}

[1] Akao Y, King B, Mazur G H. Quality function deployment: integrating customer requirements into product design[M]. Cambridge, MA: Productivity press, 1990.

[2] Akao Y, Mazur G $H$. The leading edge in QFD: past, present and future[J]. International Journal of Quality \& Reliability Management, 2003, 20(1): 20-35.

[3] Armacost. \& Mullens, M. A. An AHP framework for prioritizing customer requirements in QFD: An industrialized housing application [J]. IIE Transactions, 1994, 26(4): $72-79$

[4] Chuang. Combining the analytic hierarchy process and quality function deployment for a location decision from a requirement perspective [J]. International Journal of Advanced Manufacturing Technology, 2001, 18(11): 842-849

[5] Clausing, D. P. \& Pugh, S. J. Enhanced quality function deployment [A]. Proceedings of the Design Productivity International Conference, 1991(1): 15-25

[6] Clausing, D. P. Total Quality Development [J]. New York: American Society of Mechanical Engineering,1994, 12(5): $35-46$

[7] Cohen L, Cohen L. Quality function deployment: how to make QFD work for you [J]. 1995.

[8] Kahraman C, Ertay T, Büyüközkan G. A fuzzy optimization model for QFD planning process using analytic network approach [J]. European Journal of Operational Research, 2006, 171(2): 390-411.

[9] Li S, Ma Y, Yang G, Li Y, (2009) An integrated mode research of QFD and TRIZ and its applications. Proceedings of the 2009 second international workshop on computer science and engineering, DC, USA, pp 548-552

[10] Liang, H. L. \& Lu, IuanYuan. Product Quality as a Determinant of Product Innovation: an Empirical Analysis of the Global Automotive Industry Total Quality Management [J]. Total Quality Management, 2006,17(2): 141-147

[11] Melemez K, Di Gironimo G, Esposito G, et al. Concept design in virtual reality of a forestry trailer using a QFDTRIZ based approach [J]. Turkish Journal of Agriculture and Forestry, 2013, 37(6): 789-801.

[12] Shih-shue Sher. The Application of Quality Function Deployment in Product Development Journal of American Academy of Business, Cambridge, 2006,8(2): 292

[13] Su C T, Lin C S. A case study on the application of Fuzzy QFD in TRIZ for service quality improvement [J]. Quality \& Quantity, 2008, 42(5): 563-578.

[14] Tan R, MA J, Zhang H, et al. Study on the conceptual design process based on QFD and TRIZ [J][J]. Machine Design, 2002, 9: 000.

[15] Terninko J. The QFD, TRIZ and Taguchi connection: customer-driven robust innovation[C]//The ninth symposium on quality function deployment. 1997.

[16] Wang CS, Chang TR (2007) Integrated QFD, TRIZ and FMEA in conceptual design for product development process. Proceedings of the 13th Asia Pacific management conference, Melbourne, Australia, pp 1085-1095

[17] Wang H, Chen G, Lin Z, et al. Algorithm of integrating QFD and TRIZ for the innovative design process [J]. International Journal of Computer Applications in Technology, 2005, 23(1): 41-52.

[18] Yamashina H, Ito T, Kawada H (2002) Innovative product development process by integrating QFD and TRIZ. Int J Prod Res 40(5):1031-1050

[19] Yeh C H, Huang J C Y, Yu C K. Integration of four-phase QFD and TRIZ in product R\&D: a notebook case study[J]. Research in Engineering Design, 2011, 22(3): 125-141. 